\title{
EPIDEMIOLOGY AND OUTCOME OF ELECTRIC BURNS AT SAIMS, A TERTIARY CARE CENTRE OF CENTRAL INDIA
}

\author{
Ajay Lunawat, S. M. Datey, Avinash Vishwani, Yashasvi Khare, Vikrant Ranjan
}
1. Associate Professor. Department of General Surgery, Sri Aurobindo Medical College and Post Graduate Institute, Indore.
2. Professor. Department of General Surgery, Sri Aurobindo Medical College and Post Graduate Institute, Indore.
3. Assistant Professor. Department of General Surgery, Sri Aurobindo Medical College and Post Graduate Institute, Indore.
4. Resident. Department of General Surgery, Sri Aurobindo Medical College and Post Graduate Institute, Indore.
5. Resident. Department of General Surgery, Sri Aurobindo Medical College and Post Graduate Institute, Indore.

\section{CORRESPONDING AUTHOR:}

Dr. Ajay Lunawat,

46, Bhagwandeen Nagar,

Indore (M.P.), India- 452001.

E-mail: drajay-lunawat@rediffmail.com

ABSTRACT: Electrical burn injury is one of the most destructive injuries seen in the casualty room of any hospital. It is a special type of injury with potential of causing significant functional disability and extensive disfigurement. This retrospective study was conducted in the Burn Unit of Sri Aurobindo Institute of Medical Sciences, Indore, a leading tertiary care centre of Central India. This study was done by us to know about the demographic pattern of victims of electrical burn in our area. We wanted to quantify the loss of life due to electrical injuries and assess the degree of disability in the survivors.This retrospective epidemiological study was conducted on patients of electric burn, admitted between Jan. 2007 and Nov. 2012 in our burn unit. We have studied 67 patients of electric burns in this study. Most of the human and economic losses caused by accidents leading to the electrical burn injuries could have been prevented. Prevention of these accidents can be done increasing social awareness and observation of basic and simple precautions by an individual which can be imbibed with the primary education.

KEY WORDS: Electric burn, accidental burn, electric injury

INTRODUCTION: Electricity is a boon to mankind. This turns into a curse, when it becomes the cause of a disaster. Most of the times the user is at fault, but unfortunately for him the results are devastating. Since its inception in 1849, commercial use of electricity has been one of the most dangerous commodities in respect of its destructive potential in our society.

Electric burn injury is one of the most destructive injuries seen in a casualty room of any hospital. It is a special type of injury with potential of causing significant functional disability and extensive disfigurement.

Electric burns can be caused by low-voltage or high-voltage currents. The intensity of electric burn depends on the voltage, current flow and tissue resistance.(ref 1,2) The damage caused by electric burn is due to two mechanisms, the local generation of heat and direct action of passage of current itself through the tissues. The heating causes coagulative necrosis of the cells and current causes disruption of cell membrane leading to cell death and tissue loss. 
To analyze the causes, effects of electric burn injuries, this retrospective study was conducted in the burn unit of Sri Aurobindo Institute of Medical Sciences (SAIMS) Indore. It is a 1100 bedded tertiary care centre catering to Central India, since its inception in September 2004.

This study was done by us to know the demographic pattern of victims of electrical burn in our area. We wanted to quantify the loss of life and degree of disability in the survivors of electric burns in our society. Disability is difficult to analyze in numerical values because it is not only physical, but has an emotional component also.

All the accidental electric burns are preventable, and it can be done by social awareness and some simple precautions by any individual which can be imbibed with the primary education.

MATERIALS AND METHODS: This retrospective epidemiological study was conducted on patients admitted to our burn unit from January 2007 to November 2012. The patients who were dead on arrival in the casualty as well as patients with electrocution but no electric burn injuries, were excluded from the study.

A detailed proforma was prepared to collect the data of all patients. We retrieved the case files of all admitted patients from the medical records department for this retrospective study Detailed data from the case files were further analyzed for any discrepancies and entered in the Master-chart for the final analysis. Data was analyzed by statistical method using percentages.

OBSERVATIONS AND DISCUSSION: We have studied a total of 67 patients of electric burn injuries admitted in our hospital's burn unit between January 2007 and November 2012 in this retrospective epidemiological study.

Seven hundred and seventy four patients were admitted to Burn Unit in this period of four years and eleven months. Thermal Burn being the most common burn injury, as depicted in table 1, comprising 698 cases (91\%), electric burns being the second most common cause of admission to the burn unit, constituting 67 cases $(8.65 \%)$.

This percentage is comparable to $7.2 \%$ incidence of electric burns in a study conducted by Sachde et al (ref 1 )

Table 1 : Distribution of burn injuries

\begin{tabular}{|l|l|l|l|}
\hline s.no & causes of burn injuries & number of patients & percentage \\
\hline 1 & thermal burns & 698 & $91.09 \%$ \\
\hline 2 & electric burns & 67 & $8.65 \%$ \\
\hline 3 & chemical burns & 9 & $1.16 \%$ \\
\hline
\end{tabular}

Table 2 : Yearly Distribution of patients admitted to SAIMS Burn Unit

\begin{tabular}{|l|l|l|l|}
\hline S.No. & year & number of electric burn & percentage of total admission \\
\hline 1 & 2007 & 03 & $2.72 \%$ \\
\hline 2 & 2008 & 02 & $1.81 \%$ \\
\hline 3 & 2009 & 04 & $3.63 \%$ \\
\hline 4 & 2010 & 18 & $10.58 \%$ \\
\hline 5 & 2011 & 16 & $8.65 \%$ \\
\hline 6 & 2012 (till oct.) & 24 & $13.79 \%$ \\
\hline
\end{tabular}


Above table is for number and percentages of electric burns patients admitted in burn unit of SAIMS between January 2007 and November 2012 . Rising numbers are indicative of the growth and recognition of a specialized unit of a multispecialty hospital.

Table 3 : Distribution of patients according to age

\begin{tabular}{|l|l|l|l|}
\hline s.no. & age group (years) & number of patients & percentage \\
\hline 1 & 0 to 10 & 3 & $4.47 \%$ \\
\hline 2 & 11 to 20 & 13 & $19.4 \%$ \\
\hline 3 & 21 to 30 & 32 & $47.76 \%$ \\
\hline 4 & 31 to 40 & 16 & $23.88 \%$ \\
\hline 5 & 41 to 50 & 2 & $2.98 \%$ \\
\hline & Above 50 & 1 & $1.49 \%$ \\
\hline
\end{tabular}

Table 4 relation between tbsa (total body surface area) and death: insult duration

\begin{tabular}{|l|l|l|l|}
\hline s.no. & tbsa of patient & death :insult duration & cause of death \\
\hline 1 & $30 \%$ & day 15 & \# cervical vertebrae \\
\hline 2 & $40 \%$ & day4 & septicemia \\
\hline 3 & $54 \%$ & day7 & septicemia \\
\hline 4 & $54 \%$ & day5 & septicemia \\
\hline 5 & $55 \%$ & day7 & acute renal failure \\
\hline 6 & $77 \%$ & day6 & ards \\
\hline
\end{tabular}

Patient with $30 \%$ TBSA and cervical cord compression died on $15^{\text {th }}$ day of injury. He underwent cervical decompression and succumbed in immediate postoperative period. All the patients who died had a TBSA of above $30 \%$.Four out of the six had TBSA above $50 \%$. Patient with $77 \%$ died of ARDS, while the one with $55 \%$ died of ARF on the $4^{\text {th }}$ day, rest of the patients died of septicemia.

DURATION OF STAY: Fifteen (22.38\%) patients of the total of 67 did not complete the treatment in the hospital and were discharged on request or discharged against medical advice. Therefore the following chart includes the 42 patients who completed the treatment in hospital.

Table 5 Average duration of stay in various groups

\begin{tabular}{|l|l|l|}
\hline tbsa in percent & average duration of stay in days & number of patients \\
\hline $1 \%$ to $5 \%$ & 10.4 & 5 \\
\hline $6 \%$ to $10 \%$ & 14.33 & 9 \\
\hline $11 \%$ to $15 \%$ & 17.29 & 6 \\
\hline $16 \%$ to $30 \%$ & 29.3 & 13 \\
\hline$>30 \%$ & 34.18 & 13 \\
\hline
\end{tabular}

Duration of stay ranges between 4 to 83 days.The overall average duration of stay comes to 23.53 days in our burn unit. Similar data were concluded in the study conducted by Haddad et al from King Hussein Medical College, Jordan(ref4).Though TBSA calculation in electric burn injuries does not signify the severity of damage, more is the TBSA, longer the stay in hospital. 
TYPE OF INJURY: All cases were the result of accidental injuries in our study. No case of suicidal or homicidal injury was encountered.

CAUSE OF INJURY: Forty five (67.16\%) were due to high tension line and remaining $22(32.84 \%)$ were caused by low tension line. This shows a clear bias towards high tension electrocution, as well as signifies that high tension lines are laid without proper planning. Residential premises are permitted to be built in near vicinity of high tension line exposing our ignorant people to danger of high tension electrocution.

Table 6: various procedures performed

\begin{tabular}{|l|l|l|}
\hline s.no. & surgical procedure performed & number \\
\hline 1 & fasciotomy & 10 \\
\hline 2 & debridement/escharotomy & 64 \\
\hline 3 & superficial skin grafting & 25 \\
\hline 4 & amputations & 17 \\
\hline 5 & intercostal drainage & 02 \\
\hline 6 & flap rotation & 02 \\
\hline 7 & cervical laminectomy & 01 \\
\hline & & \\
\hline
\end{tabular}

Fasciotomy for compartment syndrome in limbs was performed as early as possible, but was hardly able to save the patient from major amputation except in two patients. Total number of 122 surgical procedures were carried out in total 67 patients.

Amputations

Table 7 : amputations performed in various electric burn

\begin{tabular}{|l|l|l|}
\hline S.no. & type of amputation & number \\
\hline 1 & left below knee & 2 \\
\hline 2 & left above knee & 0 \\
\hline 3 & right below knee & 1 \\
\hline 4 & right above knee & 1 \\
\hline 5 & left below elbow & 3 \\
\hline 6 & left above elbow & 3 \\
\hline 7 & right below elbow & 6 \\
\hline 8 & right above elbow & 2 \\
\hline 9 & finger amputation/disarticulation & 5 \\
\hline 10 & toe amputation/disarticulation & 5 \\
\hline
\end{tabular}

Table 8 complications seen in patients of electric burn

\begin{tabular}{|l|l|l|}
\hline s.no. & complication & number of patients \\
\hline 1 & acute renal failure & 1 \\
\hline 2 & septicemia & 6 \\
\hline 3 & respiratory failure & 1 \\
\hline 4 & severe anemia & 3 \\
\hline
\end{tabular}


One female patient who suffered 35\% TBSA had acute renal failure, underwent haemodialysis seven times and was discharged with loss of Right upper limb and left lower limb. Septicemia was found to be the major cause of mortality in second-third week of treatment. Hypoproteinaemia and anemia were major nutritional deficiency in treated patients.

Not a very significant number of patients had ECG changes or electrolyte disturbances. Concomitant injuries like cerebral concussions, facial bone fractures, vertebral fractures, rib fractures were found in few patients .One had quadriplegia leading to cervical laminectomy. Two had paraplegia, one recovered well while the other one had no improvement, leading to sacro coccygeal pressure sores grade IV, requiring a fasciocutaneous rotation flap .Rib fractures leading to haemothorax which required Inter Costal Drainage in two patients.

TBSA(Total body surface area) calculation is not very important in electric burn, as we found that majority of our patients who had disability ranging from $70 \%$ to $100 \%$ had TBSA ranging from $8 \%$ to $20 \%$. Two exceptions were of patients of TBSA of $40 \%$ and $53 \%$ leading to loss of either limb, This signifies the role of myonecrosis as well as injury to neurovascular bundle. In thermal burn TBSA calculation could be used as a prognostic tool, but in electric burn, there are many other factors than TBSA calculation, which will help in deciding the outcome of the injury.

CONCLUSION: This epidemiological study on the patients of electric burn suggests that most of the human and economic losses caused by the accidents leading to electric burn injuries could have been prevented. As we have already stated general education regarding safety measures while using the electricity should be given in primary schools itself. Various government agencies should keep a close vigil on developmental activities and should not allow settlement of new colonies in near vicinity of high tension lines. We could not find any urban bias in electric burn incidences, which is contrary to western world. Thus implementation of regulatory act regarding prevention from electrical injuries are to be implemented strictly by various governmental agencies.

ACKLOWLEDGENT: We are thankful to Dr.Vinod Bhandari ,Chairman, Sri Aurobindo Institute of Medical Sciences and Postgraduate Studies for giving the permission to conduct this study. We are also thankful to Dr. P.K.Banerjee, Professor and Head of the Department of Surgery and Dr. S.D. Joshi, Dean of Sri Aurobindo Institute of Medical Sciences for allowing the publication of this study. We are also thankful to Sister Neelu and other staff member of burn unit.

\section{BIBILOGRAPHY:}

1. Jayesh Sachade, M.F. Shaikh, Manav Suri, Kinnar Kapadia, Sumit Agarwal : Electric Burns A two year study. Indian Journal of Burns ; Vol-16/issue 01/Dec 2008/19-23.

2. Handschin A E, Vetter S, Jung F J, Guggenheim M, Kunzi W, Giovanoli P : A case-matched controlled study on high voltage electrical injuries vs thermal burns; J Burn Care Res 2009 May-June; 30 (3):400-7.

3. Ali Akbar Mohmmadi, Masoud Amini, Davood Mehrabani, Zohreh Kiani, Azam Seddigh: A survey on 30 months electrical burns in Shiraz university of Medical Sciences Burn Hospital ; burns 34 (2008) 111-113.

4. Haddad S.Y. : ELECTRICAL BURN- A FOUR YEAR STUDY ; Annals of Burn and Fire Disasters - Vol XXI - 2- June 2008. 


\section{ORIGINAL ARTICLE}

5. Haberal M, Kaynaroglu V, Oner I, Golay k, Bayraktar U, Bigin N : Epidemiology of Electric burns in our centre ; Annals of the MBC - Vol.2-n'1-March 1989.

Chart 1:

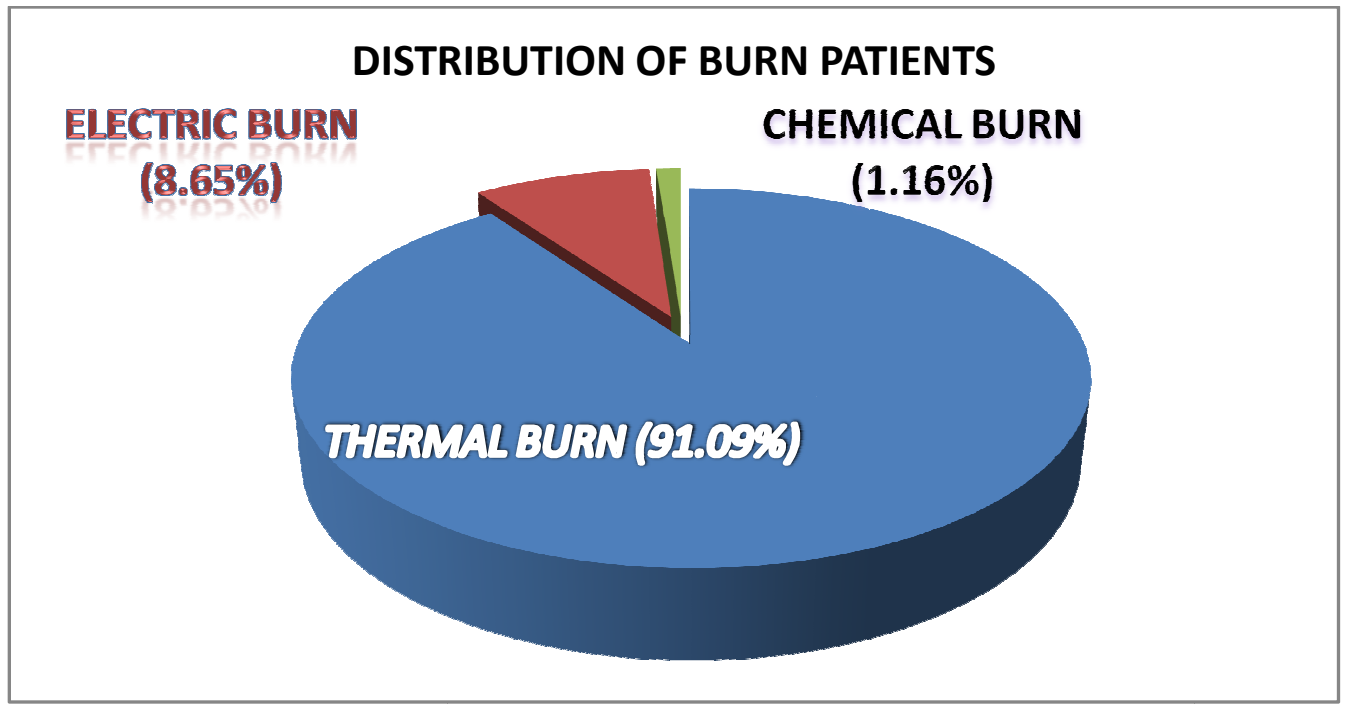

chart 2 :

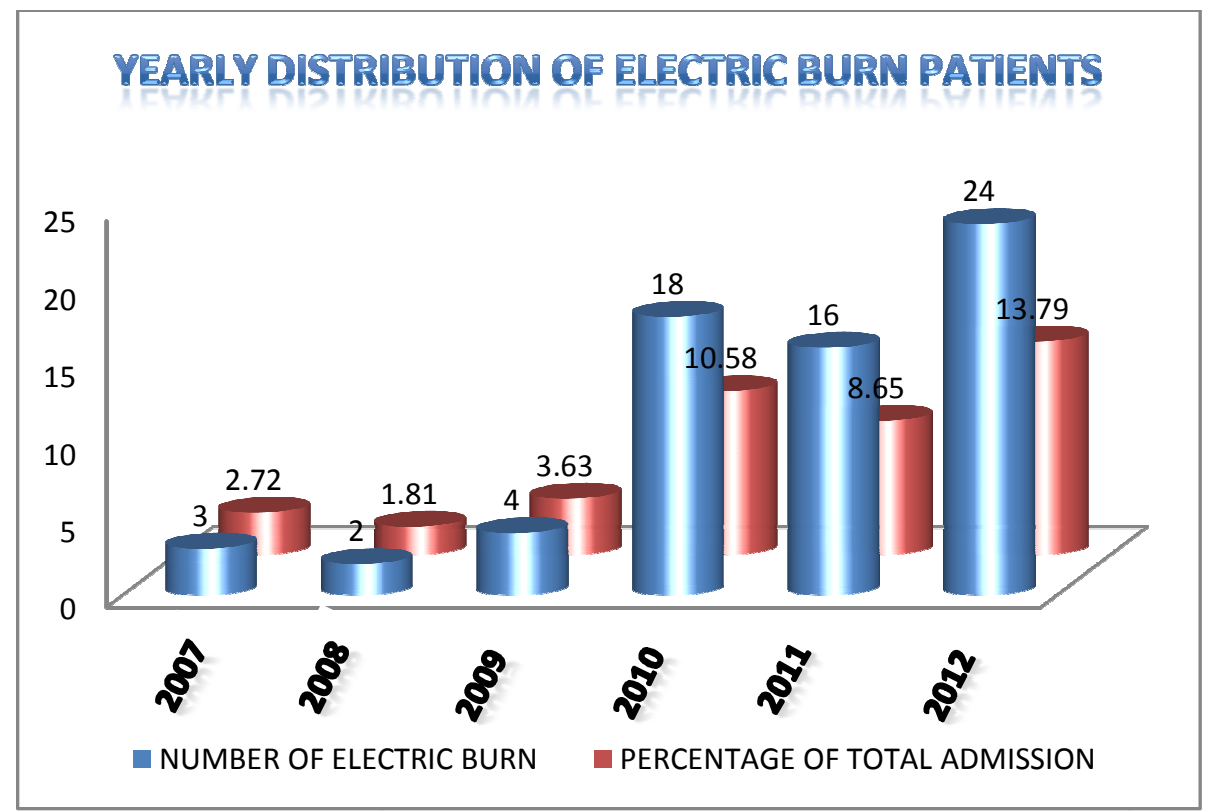


CHART NO. 3

\section{DISTRIBUTION OF PATIENTS ACCORDING TO AGE GROUPS}

$\square 0$ to $10 \square 11$ to $20 \square 21$ to $30 \square 31$ to $40 \square 41$ to $50 \square 50$ and above $3 \% \quad 2 \% \quad 4 \%$

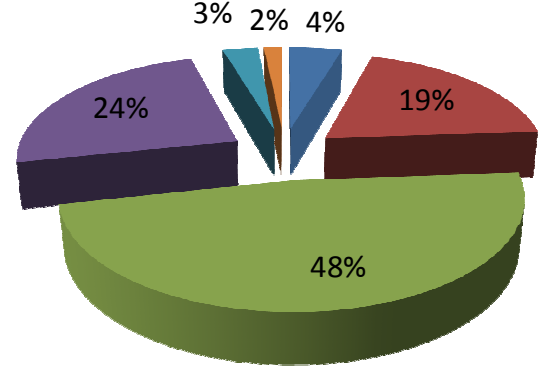

CHART 4 :

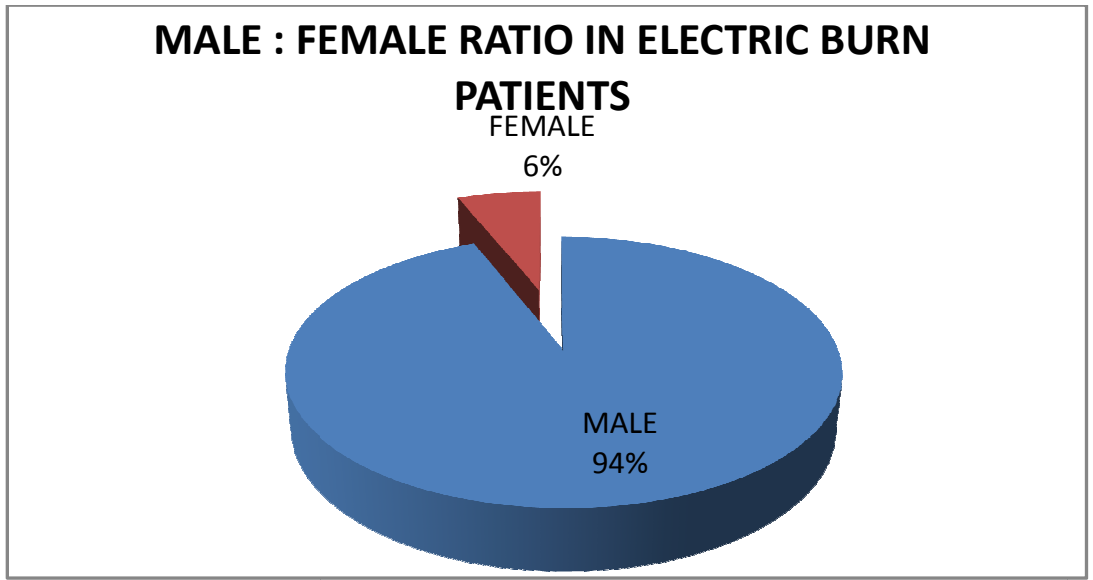

CHART 5 :

\section{DISTRIBUTION ACCORDING TO MARITAL STATUS}
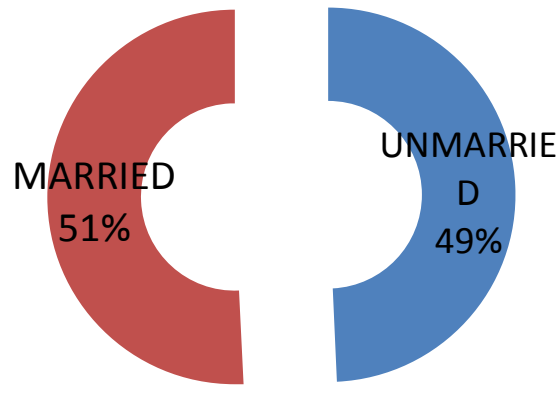
CHART 6 :

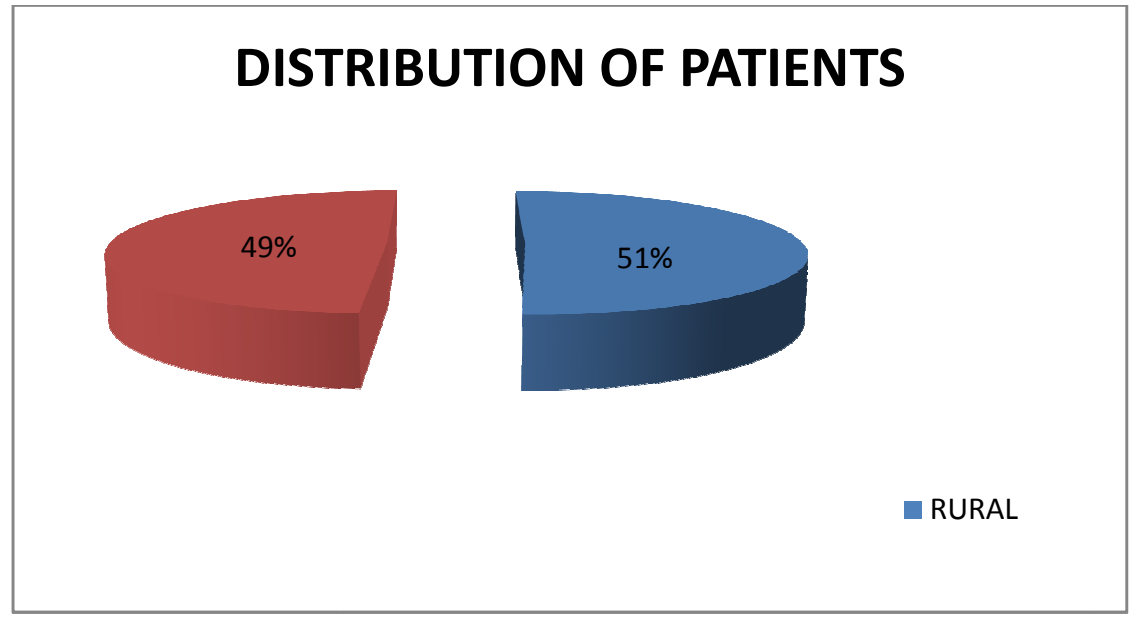

CHART NO. 7 :Mortality Statistics in Burn unit.

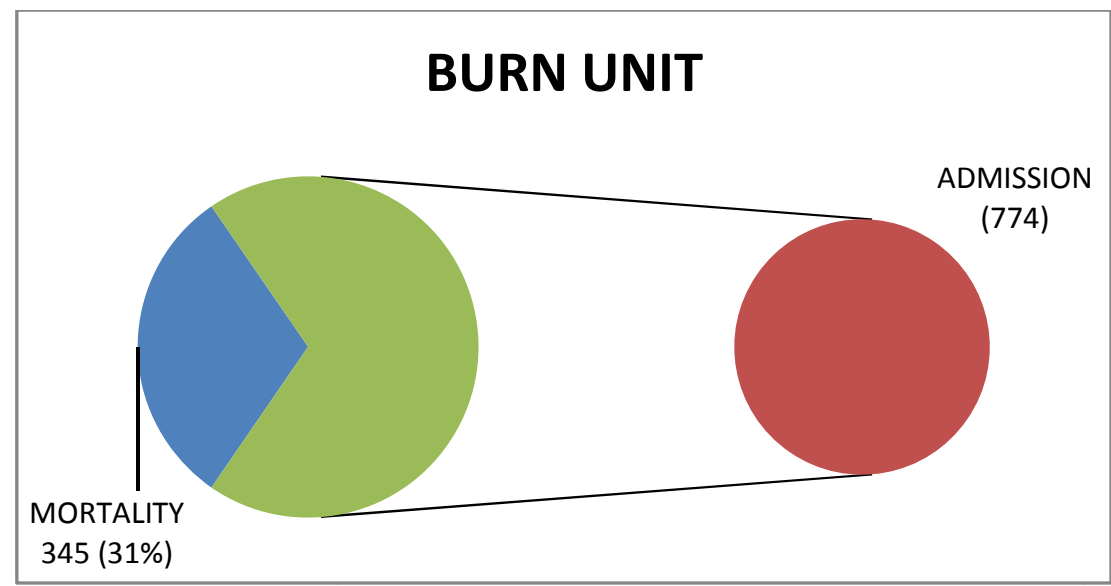

CHART N0.8 :Mortality Statistics of electric Burn

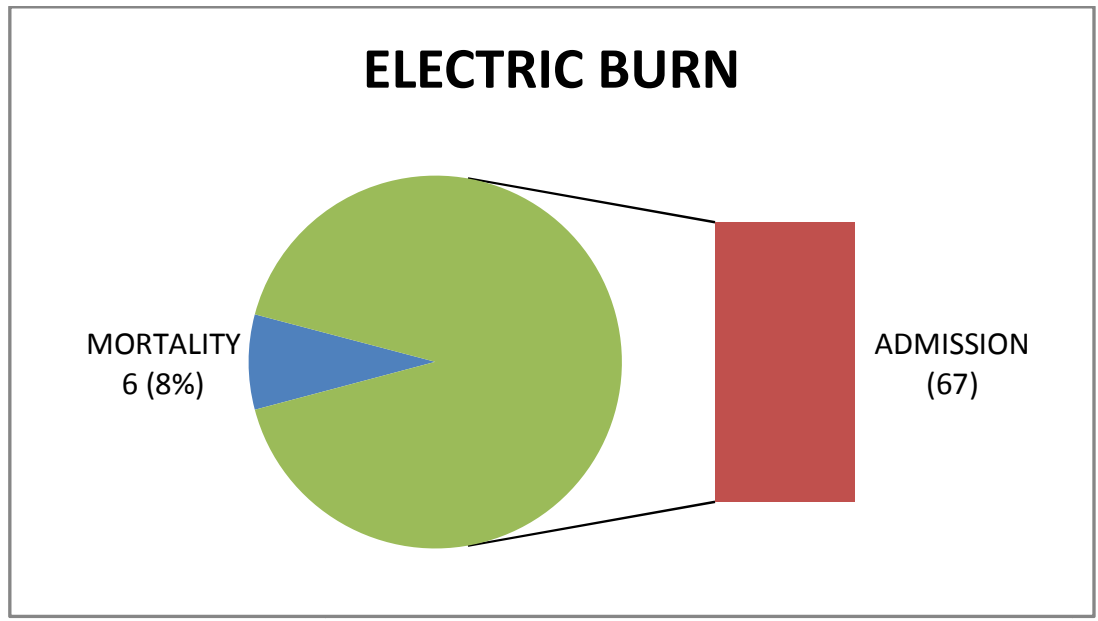




\section{ORIGINAL ARTICLE}

CHART NO. 9 :Interval Between Injury and Death

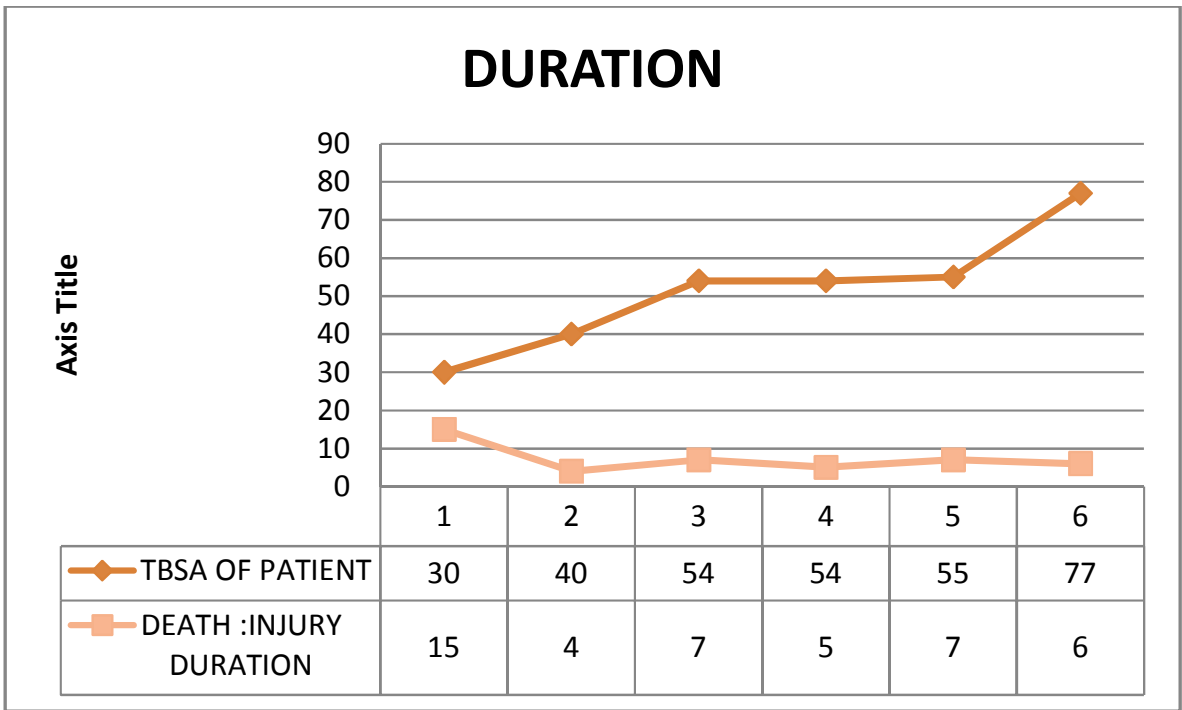

CHART NO. : 10

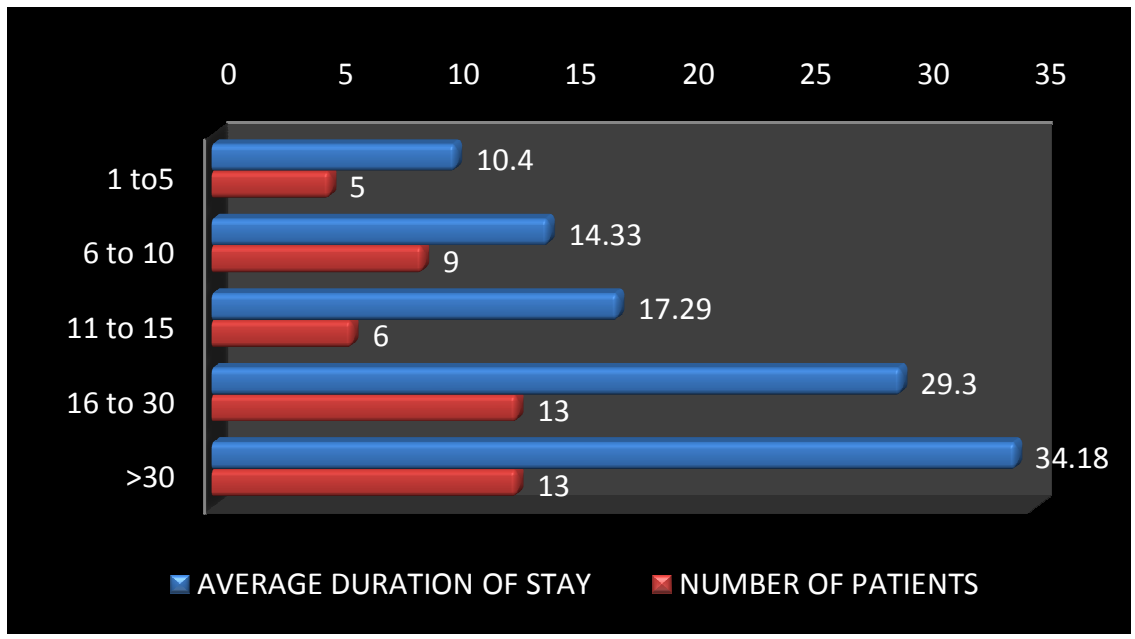

CHART NO. 11

\section{DISTRIBUTION OF ELECTRIC BURN}

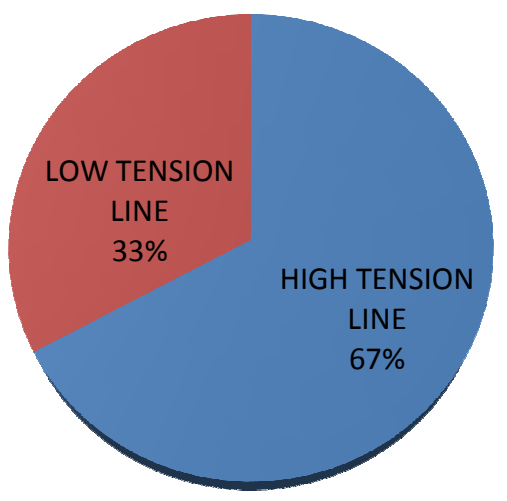


CHART NO. 12

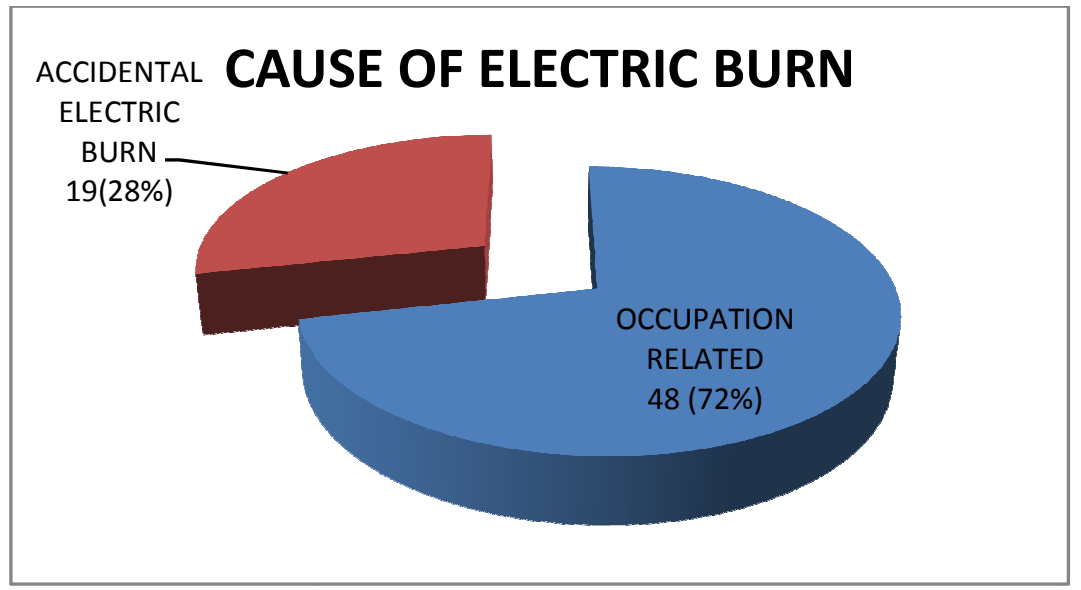

